\title{
Growth and differentiation of conducting airway epithelial cells in culture
}

\author{
R. Wu, Y.H. Zhao, M.M.J. Chang
}

Growth and differentiation of conducting airway epithelial cells in culture. R. Wu, Y.H. Zhao, M.M.J. Chang. (CERS Journals Ltd 1997.

ABSTRACT: The development of routine techniques for the isolation and in vitro maintenance of conducting airway epithelial cells in a differentiated state provides an ideal model to study the factors involved in the regulation of the expression of mucociliary differentiation. Several key factors and conditions have been identified. These factors and conditions include the use of biphasic culture technique to achieve mucociliary differentiation, the use of such stimulators as the thickness of collagen gel substratum, the calcium level, and vitamin A, and such inhibitors as the growth factors, epidermal growth factor and insulin, and steroid hormones, for mucous cell differentiation. Using the defined culture medium, the life cycle of the mucous cell population in vitro has been investigated. It was demonstrated that the majority of the mucous cell population in primary cultures is not involved in the replication of deoxyribonucleic acid (DNA). However, the mucous cell type is capable of self-renewal in culture, and this reproduction is vitamin A dependent. Furthermore, differentiation from nonmucous to mucous cell type can be demonstrated by adding back a positive regulator such as vitamin A to the "starved" culture. Cell kinetics data suggest that vitamin A-dependent mucous cell differentiation in culture is a DNA replication-independent process, and the process is inhibited by transforming growth factor- $\beta 1$.

Eur Respir J 1997; 10: 2398-2403.

California Regional Primate Research Center and Dept of Internal Medicine, University of California, Davis, California, USA

\section{Correspondence: R. Wu}

California Regional Primate Research Center University of California

Davis

CA 95616

USA

Received: February 241997

Accepted: February 261997

Keywords: Airway epithelium

growth factor

mucin

primary culture

retinoid cell differentiation

The project was supported in part by grants from NIH (HL35635, HL54678, ES06230) and the American Cancer Society.
The epithelial lining of conducting airways provides a barrier and first line of defence against inhaled particles and toxic gases. Two properties inside the epithelium are essential elements of the defence mechanism. One is the production of mucus, which plays a major role in trapping inhaled particles before they reach the epithelium; the other is the ciliary beating that moves these particles trapped in mucus to the larynx, where they are then swallowed. The cell type responsible for the ciliary beating is the ciliated cell type. This is regarded as a terminal cell type and is not involved in the renewal of airway epithelium [1]. Ciliated cells have proven to be relatively stable under both the in vivo hostile environment and the in vitro culture condition. The cell type responsible for mucus production in the surface airway epithelium is the mucous cell type. Other cell types located in the submucosal gland region also contribute to mucus production. Our study focuses on the differentiation of mucous cells of surface airway epithelium. Mucin, the major component responsible for the vasoelastic properties of mucus [2], is produced by these cells. Airway injury or disease often results in the compromise of this protective function by the overproduction and/or alteration in the content of airway mucin. The nature of this alteration is largely unknown.
To understand the nature of mucus production, a number of in vitro models, including the organ culture and the cell culture systems, have been developed [3-6]. In this communication, we focus on the cell culture model that permits epithelial cells to express ciliogenesis and mucous glycoprotein synthesis. We use this model to study the regulation of the mucin synthesis by various microenvironmental nutrients.

\section{Cell culture model of airway epithelial cells}

The development of serum-free hormone-supplemented medium

Airway epithelial cells can be cultivated in vitro over long periods in numerous ways. Techniques have been developed that allow us to obtain viable epithelial cells from different airway regions [7, 8]. These epithelial cells, in most cases, are cultivated in a serum-free medium supplemented with a mixture of hormones and growth factors [4-6]. In a serum-supplemented medium, we observed limited cell proliferation and short life span, except in a few cases when airway epithelial cells were cultivated in the presence of a low amount of serum. MAsui et al. [9] were first to show that this limited

Previous articles in this series: No. 1: P.K. Jeffery, D. Li. Airway mucosa: secretory cells, mucus and mucin genes. Eur Respir J 1997; 10: 1655-1662. No. 2: W.D. Kim. Lung mucus: a clinician's view. Eur Respir J 1997; 10: 1914-1917. No. 3: L.D. Martin, L.G. Rochelle, B.M. Fischer, T.M. Krunkosky, K.B. Adler. Airway epithelium as an effector of inflammation: molecular regulation of secondary mediators. Eur Respir $J$ 1997; 10: 2139-2146 
proliferation is due to the presence of transforming growth factor (TGF)- $\beta$ in the serum. TGF- $\beta$ is a potent growth inhibitor for airway epithelial cells. This limited proliferation is consistent with the discovery made many years ago by BotTENSTEIN et al. [10] that cell growth, especially of the epithelial cell type, is regulated by hormones and various growth factors. Based on the response of primary airway epithelial cells to various growth factors, we have systematically developed a serum-free hormone-supplemented medium for growth of various airway epithelial cells derived from different ages and airway segments, including those from foetus and distal airways. The hormonal growth supplements used in our study are as follows: insulin, transferrin, epidermal growth factor, hydrocortisone, cholera toxin, bovine hypothalamus extract, and retinol. Except for retinol, the physiological significance of these supplements in vivo is still unknown. Using this defined medium, up to five passages and 25-30 population doublings have been demonstrated in airway epithelial cells obtained from an adult human [6].

In contrast with epithelial development under cell proliferation conditions, the development of a culture condition for ciliogenesis and mucous cell differentiation has been more troublesome. Developing an ideal culture condition for airway mucociliary cell differentiation is difficult in part because of the complexity of the regulation of cell differentiation, so that the life cycle of various airway epithelial cell types is still unresolved. For mucous glycoprotein synthesis, the complexity includes regulation at the transcriptional and translational levels, glycosylational steps, and processes involved in storage and secretion. We are also hindered by our limited knowledge of the biochemical and genetic structures of large molecular weight mucous glycoproteins. The complex structures and the diverse types of mucins are well recognized. In order to elucidate airway mucin synthesis in culture, previous studies had to rely on characteristics of several biochemical properties of mucin, such as the amino acid and carbohydrate compositions, the molecular size and enzymatic characterization, and the presence of O-glycosidic bonds in the isolated molecules [2, 11-13]. Since few biochemical or genetic probes are available for quantifying mucin synthesis, using these characteristics is initially essential in order to ascertain the mucin-like synthesis. However, these characteristics cannot be used practically in the routine quantification of mucin synthesis and mucous cell population in culture. Several monoclonal antibodies that are useful in the identification of mucous cell population and the quantification of mucin synthesis have recently been developed [14-16]. These antibodies are specific to airway mucin and secretory mucus granules. Only recently has mucous cell differentiation been studied at the genetic level. Several putative apomucin complementary deoxyribonucleic acid (cDNA) clones have been used as probes for measuring the messenger ribonucleic acid (mRNA) level of a specific apomucin gene [17-21].

\section{Evidence of mucociliary cell differentiation in culture}

The primary culture system of hamster tracheal epithelial cells is the first in vitro demonstration of mucous cell differentiation [11-13] and ciliogenesis $[12,22]$. The culture system was identical to the serumfree hormone-supplemented medium for cell growth except for the use of a collagen gel substratum. Evidence of mucous cell differentiation in the hamster culture was based on the biochemical analyses of mucin-like synthesis, such as the molecular size and the enzymatic digestion, the compositional analyses of the secretion, and the presence of mucous granules in cultured cells. Furthermore, the quantitative kinetics and the time-course studies suggest that the mucous cell population in the hamster culture is derived from the undifferentiated cell type. Evidence of in vitro mucous cell differentiation has now been extended to cultures derived from monkey [23, 24], human [6], rabbit [25], and guinea pig [26] airway tissues. Recently, the development of mucinspecific monoclonal antibodies allow us to use both the enzyme-linked immunosorbent assay (ELISA) [16] and immunohistochemical methods [6] to quantify mucin production and mucous cell population, respectively, in culture. Data obtained from these two methods are further supported by the morphological characterization. Using these two quantitative methods, several in vitro parameters affecting mucous cell differentiation have been investigated in human and monkey cultures.

The other advance in culturing airway epithelial cells in vitro is the development of a biphasic culture system in which epithelial cells are maintained in air-liquid medium interface [26-29]. This new culture system reflects the in vivo situation and allows further cell differentiation. We have observed mucociliary differentiation of cultured human and monkey airway epithelial cells that are maintained in the biphasic culture under basal feeding but not under the traditional immersed feeding. A similar observation has been demonstrated by other investigators $[30,31]$. This development supports the feasibility of studying the mechanisms and factors that are involved in the regulation of mucociliary differentiation in vitro. However, we found that it is still difficult at this moment to carry out the study related to ciliogenesis for lack of a method of quantitatively assessing ciliogenesis. For mucous cell differentiation, both ELISA and immunocytochemistry methods have been developed for quantifying mucous cell population in culture.

\section{Effects of culture conditions on mucous cell differentiation}

\section{Effects of collagen substratum}

The collagenous substratum has been used in various cell culture systems, including respiratory epithelial cells, to promote cell proliferation and differentiation. LECHNER et al. [5] have developed a thin substratum with a mixture of type I collagen, bovine serum albumin, and fibronectin to enhance human bronchial epithelial cell attachment and proliferation. However, the effect of this type of culture system on airway epithelial cell differentiation was not studied. We used a collagen gel substratum to enhance cell proliferation of both hamster [12, 13, 22] and mouse [32] tracheal epithelial cells. It was the first quantitative demonstration that new cilia and mucous granules were formed 
in the hamster cultures that are maintained on the collagen gel substratum. These results have prompted the initiation of several studies in the differentiation of cultured airway epithelial cells derived from rabbit, guinea pig, human, and nonhuman primate tissues. All of these studies draw a similar conclusion: the expression of the airway mucous cell differentiated function is at least enhanced by a collagenous substratum. However, the presence of a collagenous membrane is still insufficient to promote new ciliogenesis in vitro except in a few cases, such as in primary hamster and guinea-pig tracheal epithelial cultures.

Recently, we observed some differences when we compared the differentiated function of mucous cells plated on the thin collagen-coated surface and the thick collagen gel (CG)-coated surface. To further understand the nature of this substratum effect, both human and primate cells were plated on CG surfaces of different thicknesses. Using both biochemical and immunological methods of mucin synthesis, we observed that the activity of mucous cell differentiation in culture is dependent on the CG thickness. In tissue culture dishes with CG less than $0.5 \mathrm{~mL}$ per $35 \mathrm{~mm}$, mucous cell function is significantly reduced. These results suggest that the optimal mucous cell differentiation in culture requires a collagen gel substratum at least $1 \mathrm{~mm}$ thick [23].

\section{Effects of calcium levels}

The importance of calcium in cell proliferation and cell differentiation has been well recognized. On a plastic surface, a low calcium $(<0.1 \mathrm{mM})$ medium prohibits epithelial cells from expressing terminal differentiation. However, the effects of calcium on airway epithelial cells grown on a CG substratum have not been investigated. We prepared our own F12 medium in which the level of calcium could be manipulated. Using this homemade F12 medium, we investigated the effects of the calcium level on mucous cell differentiation. We observed that the expression of mucous cell function is dependent on the concentration of calcium in the medium. These studies demonstrate that $>0.3 \mathrm{mM}$ calcium in culture medium is needed to achieve mucous cell differentiation [24].

\section{Effects of retinoid}

The important role of vitamin $\mathrm{A}$ and its derivatives (retinoids) in maintaining the homeostasis of airway epithelium, especially mucous cell differentiation, has been well recognized. However, the nature of this effect has not been elucidated. The development of the serumfree hormone-supplemented medium for airway epithelial cell culture provides an opportunity to elucidate the role of retinoid on the regulation of mucous cell differentiation. When vitamin A was removed from this serum-free culture medium, the expression of mucous cell function, specifically mucin synthesis, was greatly depressed in human airway cell cultures (fig. 1). This result was further supported by the electron microscopic (EM) and immunological studies. This phenomenon was

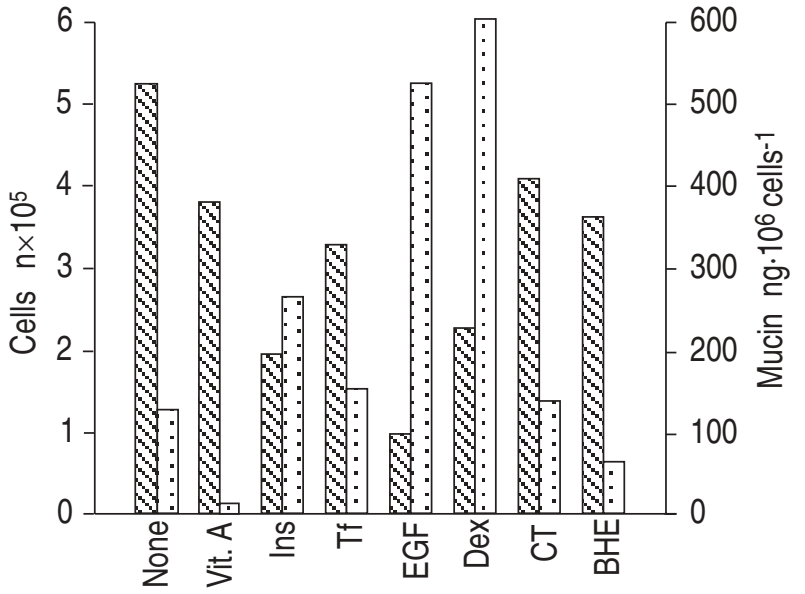

Growth supplement omitted

Fig. 1. - Effects of hormonal/growth factor supplements on cell growth $(\square)$ and mucin secretion $(\square)$ in primary cultures of human tracheobronchial epithelial cells. Protease-dissociated human tracheobronchial epithelial cells were plated on collagen gel at $5 \times 10^{4}$ cells per $35 \mathrm{~mm}$ dish in the serum-free medium supplemented with all or any six of the following seven growth supplements: insulin (Ins), transferrin (Tf), epidermal growth factor (EGF), dexamethasone (Dex), cholera toxin (CT), bovine hypothalamus extract (BHE), and vitamin A (retinol) (Vit. A). At day 8, media were changed and collected $24 \mathrm{~h}$ later. The amount of mucin in the culture media was determined by an enzyme-linked immunosorbent assay (ELISA) method using purified sputum mucin as a standard. Cell number in each dish was determined at the same time. Data represent averages from triplicate dishes.

not observed when other growth supplements were removed from the culture medium. Similar observations have been described in primary epithelial cultures of hamster and monkey airways. These results are consistent with studies performed in both in vivo and in vitro organ culture systems, suggesting that vitamin A plays a stimulatory role in the regulation of mucous cell differentiation.

Table 1. - Effects of steroid hormone and thyroxine hormone $\left(\mathrm{T}_{3}\right)$ on mucin production in primary cultures of human tracheobronchial epithelial cells

\begin{tabular}{lcr}
\hline & \multicolumn{2}{c}{ Mucin production** ng.106 cells $^{-1} \cdot 24 \mathrm{~h}^{-1}$} \\
\cline { 2 - 3 } Culture condition* & - Vitamin A & + Vitamin A \\
\hline- & $8.25 \pm 1.21$ & $31.20 \pm 2.56$ \\
$+\mathrm{HC}$ & $4.05 \pm 0.52$ & $19.81 \pm 0.98$ \\
$+\mathrm{Dex}$ & $4.13 \pm 1.21$ & $18.89 \pm 1.57$ \\
$+\mathrm{T}_{3}$ & $5.50 \pm 0.87$ & $22.88 \pm 1.89$ \\
$+\mathrm{HC}+\mathrm{T}_{3}$ & $4.15 \pm 0.53$ & $16.71 \pm 1.56$ \\
\hline
\end{tabular}

*: primary cultures of human tracheobronchial epithelial cells were grown on a collagen gel substratum in an F12 medium supplemented with $1.8 \mathrm{mM} \mathrm{CaCl}_{2}$, and insulin, transferrin, cholera toxin, EGF, and bovine hypothalamus extract [23]. At day 2, vitamin A (retinol, $1 \mu \mathrm{M})$, hydrocortisone (HC, $1 \mu \mathrm{M})$, dexamethasone $(0.1 \mu \mathrm{M})$, and $\mathrm{T}_{3}(0.03 \mu \mathrm{M})$ were added as indicated. Media were changed every other day. Media were collected at day 9-10 and used for mucin-ELISA quantitation [16]. Cell number in each dish was determined at day 10 and was used as the cell density in the calculation. **: mucin ELISA method was carried out as described in the previous publication [16] using the purified mucin of human airway sputum. The reference mucin was expressed as the amount of protein based on the amino acid composition analysis. Data were obtained from four dishes of each culture condition and expressed as mean $\pm \mathrm{SD}$. For further definitions, see legend to figure 1 . 


\section{Effects of other steroid hormones and growth factors}

The removal of several growth factors, such as insulin and EGF, from the culture medium caused a severe reduction in cell number but had a stimulatory effect on mucin synthesis activity on a per cell basis (fig. 1). These results suggest that these growth-promoting factors are inhibitors of mucous cell differentiation. In the case of the glucocorticoid steroid hormone, the cell number decreased slightly in the minus hydrocortisone culture condition. However, mucin synthesis was greatly stimulated in the absence of this steroid hormone (fig. 1). To further understand the effect of steroids, we investigated the effects of the thyroxine hormone $\left(\mathrm{T}_{3}\right)$, since this chemical has a similar nuclear receptor as the one for the glucocorticoid steroid. As shown in table 1, $\mathrm{T}_{3}$ has an inhibitory effect on the expression of mucin synthesis. This inhibition is less than that caused by hydrocortisone (HC) and dexamethasone (Dex). Furthermore, neither $\mathrm{HC}$ nor $\mathrm{T}_{3}$ can replace the role of vitamin A in stimulating mucous cell function. These studies suggest that steroid hormones and $\mathrm{T}_{3}$ are inhibitors of mucous cell differentiation. Further studies are needed to elucidate the regulation.

\section{Plasticity of mucous cell differentiation in culture}

\section{Plasticity of vitamin A-mediated mucous cell differenti- ation}

One of the benefits of using an in vitro approach is the ability to manipulate the level of the growth supplement of interest in the culture medium. By depleting or adding this growth supplement to the culture environment, the response of cells to this growth supplement can be analysed in detail. Using this type of approach, we studied the plasticity of in vitro mucous cell differentiation in response to vitamin $\mathrm{A}$. We showed that the expression of mucous cell function, measured as mucin production, in the "vitamin A starved" cultures can be re-initiated with the addition of vitamin A (fig. 2). However, the activity of this re-initiation phe-

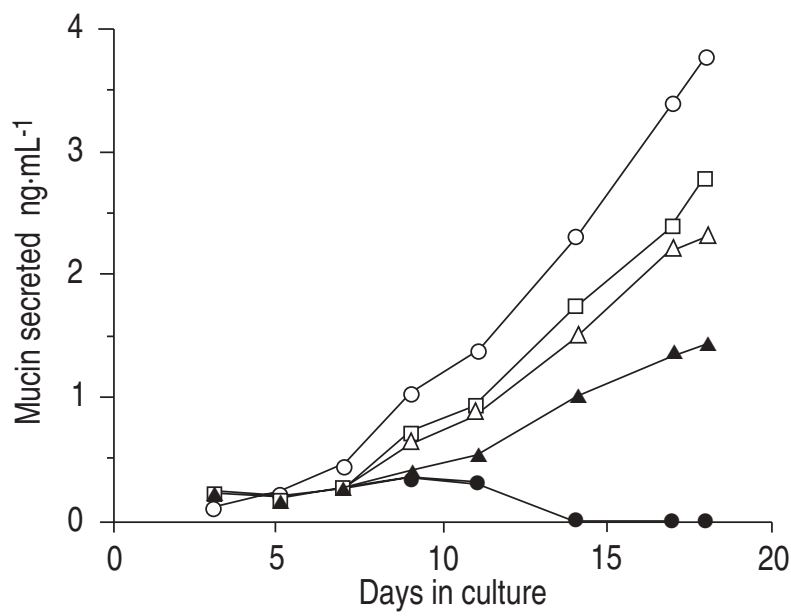

Fig. 2. - Time-course effects of vitamin A treatment on primary cultures starved of vitamin A. Human tracheobronchial epithelial cells were plated on a collagen gel substratum in a vitamin A-free medium $(\bigcirc)$. Retinol $(1 \mu \mathrm{M})$ was added after $1(\bigcirc), 3(\square), 4(\Delta)$, and 7 $(\boldsymbol{\Delta})$ days. Media were collected every day and the mucin content was determined by an enzyme-linked immunosorbent assay method. nomenon decreased with culture time. This result suggests that the response of cultured cells to vitamin A is time dependent and the plasticity of the response is quite unstable in culture. To further understand the nature of this effect, we conducted the following experiments to determine the origin of mucous cell population in culture and the response of this population to vitamin A treatment.

\section{Origin of the mucous cell population in cultures}

Mucous cells are not a terminal cell type. In a normal, uninjured state, in vivo mucous cells are capable of incorporating ${ }^{3} \mathrm{H}$-thymidine into their deoxyribonucleic acid (DNA) [1]. It has been suggested that mucous cells serve as a progenitor cell type responsible for the regeneration of airway epithelium in response to injury [1]. This role is less clear in the in vitro culture since the progenitor-precursor relationship is not as apparent as that existing in vivo.

A 4 day old vitamin A-treated culture of human tracheobronchial epithelial cells was labelled with ${ }^{3} \mathrm{H}$-thymidine for $2 \mathrm{~h}$. After the labelling, the culture was chased with cold thymidine and the cultured cells were harvested at different times. We observed that $25 \%$ of the cell population incorporated the ${ }^{3} \mathrm{H}$-thymidine during the $2 \mathrm{~h}$ labelling (table 2). Among the labelled cells, $25 \%$ stained with mucin-specific antibody (designated as $\mathrm{M}+\mathrm{N}+$ in table 2 ). After $48 \mathrm{~h}$ chase, the labelling index increased to $70 \%$ of the total cell population. Among the radioactively labelled cells, 30\% stained with the mucin antibody. These results suggest that half of the mucous cell population was from the replicative

Table 2. - Effects of vitamin A on the life cycle of primary cultures of human tracheobronchial epithelial cells

\begin{tabular}{lcccccc}
\hline & \multicolumn{5}{c}{ Cell type distribution* } \\
\cline { 2 - 7 } Culture condition** & M+/N+ & M+/N- & M-/N+ & M-/N- & Total \\
\hline + Vit. A, day 4 & $\mathrm{n}$ & 22 & 153 & 66 & 134 & 357 \\
& $\%$ & 6.2 & 37.8 & 18.5 & 37.5 & 100 \\
Chase 2 days & $\mathrm{n}$ & 55 & 53 & 125 & 23 & 256 \\
& $\%$ & 21.5 & 20.7 & 48.8 & 9.0 & 100 \\
- Vit. A, day 4 4 & $\mathrm{n}$ & 0 & 70 & 87 & 193 & 350 \\
& $\%$ & 0 & 20.0 & 24.8 & 55.1 & 100 \\
Chase 2 days & $\mathrm{n}$ & 0 & 48 & 303 & 54 & 405 \\
& $\%$ & 0 & 11.9 & 74.8 & 13.3 & 100 \\
\hline
\end{tabular}

Values are absolute numbers, or percentages. *: Cell type distribution was examined under a light microscope with a $40 \times$ objective lens. Dissociated cultured cells were cytospun on a glass slide and fixed in methanol:acetone (1:1). Slides were stained with the mucin-specific antibody by the Vectastain ABC peroxidase system [14]. After immunostaining, slides were counter-stained with toludine blue, and coated with the L-4 emulsion (Polyscience Inc. Warrington, PA, USA). Autoradiograph was carried out at $4^{\circ} \mathrm{C}$ for 2 weeks in the dark. Cells stained with the mucin-specific antibody are brown and designated as M+. Cells not stained by this antibody are blue and designated as M-. Cell nucleus labelled by ${ }^{3} \mathrm{H}$-thymidine is shown as $\mathrm{N}+; \mathrm{N}$ - indicates no incorporation. $* *$ : primary human tracheobronchial epithelial cells were maintained on a collagen gel substratum as described in table 1 . At day 2, vitamin A was added, and at day 4, cultures were pulse labelled with ${ }^{3} \mathrm{H}$-thymidine $\left(5 \mu \mathrm{Ci} \cdot \mathrm{mL}^{-1}\right)$ for $1 \mathrm{~h}$, then chased with fresh medium for 2 days. Vit.: vitamin. 
Table 3. - Effects of vitamin A on the life cycle of primary cultures of human tracheobronchial epithelial cells in culture

\begin{tabular}{|c|c|c|c|c|c|c|}
\hline \multirow{2}{*}{$\begin{array}{l}\text { Chase } \\
\text { Culture } \\
\text { condition* }\end{array}$} & \multirow[b]{2}{*}{$\mathrm{h}$} & \multicolumn{5}{|c|}{ Cell type distribution* } \\
\hline & & $\mathrm{M}+/ \mathrm{N}+$ & $\mathrm{M}+/ \mathrm{N}-$ & $\mathrm{M}-/ \mathrm{N}+$ & $\mathrm{M}-/ \mathrm{N}-$ & Total \\
\hline \multirow[t]{3}{*}{ Vitamin A } & 0 & $\begin{array}{c}0 \\
(0)\end{array}$ & $\begin{array}{c}15 \\
(5.2)\end{array}$ & $\begin{array}{c}18 \\
(6.3)\end{array}$ & $\begin{array}{c}253 \\
(88.5)\end{array}$ & $\begin{array}{c}286 \\
(100)\end{array}$ \\
\hline & 24 & $\begin{array}{c}0 \\
(0)\end{array}$ & $\begin{array}{c}4 \\
(0.9)\end{array}$ & $\begin{array}{c}136 \\
(31.1)\end{array}$ & $\begin{array}{c}298 \\
(68.0)\end{array}$ & $\begin{array}{c}438 \\
(100)\end{array}$ \\
\hline & 48 & $\begin{array}{c}0 \\
(0)\end{array}$ & $\begin{array}{c}4 \\
(0.9)\end{array}$ & $\begin{array}{c}129 \\
(28.9)\end{array}$ & $\begin{array}{c}314 \\
(70.2)\end{array}$ & $\begin{array}{c}447 \\
(100)\end{array}$ \\
\hline \multirow[t]{3}{*}{$\begin{array}{l}+ \text { Vitamin A } \\
\text { at day } 8\end{array}$} & 0 & $\begin{array}{c}2 \\
(1.3)\end{array}$ & $\begin{array}{c}10 \\
(6.7)\end{array}$ & $\begin{array}{c}11 \\
(7.4)\end{array}$ & $\begin{array}{c}126 \\
(84.6)\end{array}$ & $\begin{array}{l}149 \\
(100)\end{array}$ \\
\hline & 24 & $\begin{array}{c}4 \\
(1.8)\end{array}$ & $\begin{array}{c}38 \\
(17.5)\end{array}$ & $\begin{array}{c}51 \\
(23.5)\end{array}$ & $\begin{array}{c}124 \\
(57.1)\end{array}$ & $\begin{array}{c}217 \\
(100)\end{array}$ \\
\hline & 48 & $\begin{array}{c}12 \\
(4.1)\end{array}$ & $\begin{array}{c}76 \\
(25.9)\end{array}$ & $\begin{array}{c}86 \\
(29.3)\end{array}$ & $\begin{array}{c}120 \\
(40.8)\end{array}$ & $\begin{array}{c}294 \\
(100)\end{array}$ \\
\hline
\end{tabular}

Values are absolute numbers, with percentages in parentheses. *: human primary tracheobronchial epithelial cells were maintained on a collagen gel substratum in the serum-free medium without vitamin A. At day 8 , half of the cultures were treated with vitamin A (retinol, $1 \mathrm{mM}$ ). At the same time, these cultures were treated with $3 \mathrm{H}$-thymidine for $1 \mathrm{~h}(0 \mathrm{~h})$. The cultures were then chased with the fresh medium for 24 and $48 \mathrm{~h}$. For definitions and details of cell type identification, see table 2 .

pool of either mucous or nonmucous cell populations. However, half of the mucous cells in this study were not derived from the replication pool. In the case of nonmucous cells in culture, less than $20 \%$ were not derived from the replication pool.

In contrast to the above results, the labelling index in the absence of vitamin A was $25 \%$, and none of these labelled cells were stained by the mucin-specific antibody even though $20 \%$ of nonlabelled cells stained by this antibody were observed in this culture (table 2). After $48 \mathrm{~h}$ chase, the labelling index was $75 \%$, but none of the labelling was incorporated into the cells stained with the mucin-specific antibody. These results suggest that vitamin A has two significant effects on the life cycle of mucous cell population in culture: it is required for the replication pool of mucous cell population, and the conversion from nonmucous cell type to mucous cell type is vitamin A dependent.

\section{Role of DNA replication in vitamin A-induced mucous cell differentiation}

The above experiments established that mucous cells can be derived from the replicating pool of nonmucous cells. However, it is not clear whether DNA replication is a necessary step for this conversion. To address this question, we repeated the labelling experiment using a primary culture that was starved for vitamin A. We supplemented this culture with vitamin $\mathrm{A}$ at a later time (such as at day 8) when DNA synthesis was low. As shown in Table 3, the labelling index of this culture was $6 \%$ and none of the labelled cells were of the mucous cell type. Furthermore, the mucous cell type was about $5 \%$ of the total cell population. After 24 and $48 \mathrm{~h}$ chase, the labelled cells increased to the $30 \%$ level and again, none of them were of the mucous cell type. When vitamin A was added back to the culture, the labelling index did not change immediately. However, the mucous cell population increased to 19 and $30 \%$ at 24 and
$48 \mathrm{~h}$ chase, respectively. The mucous cells that were radioactively labelled were less than $5 \%$ of the total. These results suggest that the majority of the mucous cell population appearing in the culture after the vitamin A treatment was not derived from the replication pool. It is suggested that the conversion from nonmucous to mucous cell type by the vitamin A treatment does not require the DNA replication step.

Recently, we have begun to examine the nature of vitamin A-dependent mucous cell differentiation. Data not present in this communication (Wu and Robinson, unpublished) include the study of TGF- $\beta 1$ inhibition. We have observed that this differentiation step is inhibited by TGF- $\beta 1$ and the inhibition is a TGF- $\beta 1$ dose-dependent phenomenon.

\section{Conclusion}

The successful development of culture conditions for conducting airway epithelial cells is based on the concept developed by SATO and co-workers [10] that cell growth is regulated by hormones and growth factors. Several serum-free hormone-supplemented media have been developed to optimize epithelial cell growth. We used the defined culture system to further optimize the condition for airway mucociliary cell differentiation. These studies identified the stimulators and inhibitors involved in the regulation of mucous cell differentiation. The physiological significance of these findings remains to be elucidated. Through the defined culture condition, it is now possible to investigate the mechanisms involved in the regulation of airway epithelial cell differentiation. Vitamin $\mathrm{A}$ is an important factor involved in the in vitro regulation of mucous cell differentiation. By manipulating the level and the time of vitamin A exposure in this defined culture condition, we observed a complex scheme that generates the mucous cell population. Some of the mucous cells are self-replicating, and some of them are derived from nonreplicating, nonmucous cell type. It appears that replication of deoxyribonucleic acid is not required for the vitamin A-dependent conversion from certain nonmucous cells to mucous cells. The relationship between these different schemes needs to be explored further.

\section{References}

1. Evans MJ, Moller PC. Biology of airway basal cells. Exp Lung Res 1991; 17: 513-531.

2. Wu R, Carlson DM. Biochemical structure and expression of respiratory tract muc-ins. In: The Lung: Scientific Foundation. Crystal RG, West JB, eds. New York, Raven Press, 1990; Chapter 3.1.4.

3. Stoner GD, Katoh Y, Foidart JM, Myers GA, Harris CC. Identification and culture of human bronchial epithelial cells. Methods in Cell Biol 1980; 21A: 15-35.

4. Wu R. In vitro differentiation of airway epithelial cells. In: In vitro Models of Respiratory Epithelium. Schiff LJ, ed. Boca Raton, FL, USA, CRC Press, 1986; pp. $1-26$. 
5. Lechner JF, Stoner GD, Yoakum GH, et al. In vitro carcinogenesis studies with human tracheobronchial tissues and cells. In: In vitro Models of Respiratory Epithelium. Schiff LJ, ed. Boca Raton, FL, USA, CRC Press, 1986; pp. 143-159.

6. Wu R, Martin WR, St. George JA, et al. Expression of mucin synthesis and secretion in human tracheobronchial epithelial cells grown in culture. Am J Respir Cell Mol Biol 1990; 3: 467-478.

7. Wu R, Smith, D. Continuous multiplication of rabbit tracheal epithelial cells in a defined hormone-supplemented medium. In vitro 1982; 18: 800-812.

8. Huang TH, St. George JA, Plopper CG, Wu R. Pattern of keratin protein synthesis during the development of conducting airway epithelium in non-human primates. Differentiation 1989; 41: 78-86.

9. Masui T, Wakefield LM, Lechner JF, Harris CC. Type$\beta$ transforming growth factor is the primary differentiation inducing serum factor for normal human bronchia epithelial cells. Proc Natl Acad Sci USA 1986; 83: 2438-2442.

10. Bottenstein J, Hayashi I, Hutchings $\mathrm{S}$, et al. The growth of cells in serum-free hormone-supplemented media. Methods Enzymol 1978; 58: 94-109.

11. Kim KC, Rearick JI, Nettesheim P, Jetten AJ. Biochemical characterization of mucin secreted by hamster tracheal epithelial cells in primary culture. J Biol Chem 1985; 260: 4021-4027.

12. Wu R, Nolan E, Turner C. Expression of tracheal differentiated functions in a serum-free hormone-supplemented medium. J Cell Physiol 1985; 125: 167-181.

13. Wu R, Plopper CG, Cheng PW. Mucin-like glycoprotein secreted by cultured hamster tracheal epithelial cells: biochemical and immunological characterization. Biochem J 1991; 277: 713-718.

14. St. George JA, Cranz DL, Zicker S, Etchison JR, Dungworth DL, Plopper CG. An immunohistochemical characterization of rhesus monkey respiratory secretions using monoclonal antibodies. Am Rev Respir Dis 1985; 132 556-563.

15. Basbaum CB, Chow A, Macher BA, Finkbeiner WE Veissiere D, Foresberg LS. Tracheal carbohydrate antigens identified by monoclonal antibodies. Arch Biochem Biophys 1986; 249: 363-373.

16. Lin H, Carlson DM, St. George JA, Plopper CG, Wu R. An ELISA method for the quantitation of tracheal mucins from human and non-human primates. Amer $J$ Resp Cell Mol Biol 1989; 1: 41-48.

17. Eckhardt AE, Timpte CS, Abernethy JL, Toumadje A, Johnson Jr NC, Hill RL. Structural properties of porcine submaxillary gland apomucin. J Biol Chem 1987; 263: 1081-1088.

18. Gendler SJ, Taylor-Papadimitriou J, Duhig T, Rothbard $\mathrm{J}$, Burchell J. A highly immunogenic region of human polymorphic epithelial mucin expressed by carcinomas is made up of tandem repeats. J Biol Chem 1988; 263 : 1282-1283.

19. Gum JR, Byrd JC, Hicks JW, Toribara NW, Lamport DTA, Kim YS. Molecular cloning of human intestinal mucin cDNAs. J Biol Chem 1989; 264: 6480-6487.

20. Gum JR, Hicks JW, Swallow DM, Kim YS. Molecular cloning of cDNAs derived from a novel human intestinal mucin gene. Biochem Biophys Res Commun 1990; 171: 407-415

21. Aubert JP, Porchet N, Crepin M, et al. Evidence for different human tracheobronchial mucin peptides deduced from nucleotide cDNA sequences. Am J Respir Cell Mol Biol 1991; 5: 175-185.

22. Lee TC, Wu R, Brody AR, Barrett JC, Nettesheim P. Growth and differentiation of hamster tracheal epithelial cells in culture. Exp Lung Res 1983; 6: 27-45.

23. Robinson CB, Wu R. Culture of conducting airway epithelial cells in serum-free medium. J Tiss Cult Method 1991; 13: 95-102.

24. Martin WR, Brown C, Zhang YJ, Wu R. Growth and differentiation of primary tracheal epithelial cells in culture: regulation by extracellular calcium. J Cell Physiol 1991; 147: 138-148.

25. Rearick JI, Deas M, Jetten AM. Synthesis of mucous glycoproteins by rabbit tracheal cells in vitro: modulation by substratum, retinoids, and cyclic AMP. Biochem $J$ 1987; 242: 19-25.

26. Adler KB, Cheng PW, Kim KC. Characterization of guinea pig tracheal epithelial cells maintained in biphasic organotypic culture: cellular composition and biochemical analysis of released glycoconjugates. Am J Respir Cell Mol Biol 1990; 2: 145-154.

27. Wu R, Sato GH, Whitcutt JM. Developing differentiated epithelial cell cultures: airway epithelial cells. Fundam Appl Toxicol 1986; 6: 580-590.

28. Adler KB, Schwarz JE, Whitcutt MJ, Wu R. A new chamber system for maintaining differentiated guinea pig respiratory epithelial cells between air and liquid phases. Biochtechniques 1987; 5: 462-465.

29. Whitcutt JM, Adler KB, Wu R. A biphasic chamber system for maintaining polarity of differentiation of cultured respiratory tract epithelial cells. In Vitro Cell Dev Biol 1988; 24: 420-428.

30. DeJong PM, van Sterkenburg MAJA, Hesseling SC, et al. Ciliogenesis in human bronchial epithelial cells cultured at the air-liquid interface. Am J Respir Cell Mol Biol 1994; 10: 271-277.

31. Gray TE, Guzman K, Davis CW, Abdullah LH, Nettesheim P. Mucociliary differentiation of serially passaged normal human tracheobronchial epithelial cells. Am J Respir Cell Mol Biol 1996; 14: 104-112.

32. Nedrud JG, Wu R. In vitro mouse cytomegalovirus (MCMV) infection of mouse tracheal epithelial cells require the presence of other cell type. J Gen Virol 1984; 65: 671-679. 